\title{
Understanding Media Consumption of Electronic Sports through Spectator Motivation, Using Three Different Segmentation Approaches: The Levels of Addiction, Passion, and Fan Identification
}

\author{
Chulhwan Choi ${ }^{1}$ \\ ${ }^{1}$ Kyung Hee University, Department of Golf Industry, College of Physical Education, Yongin, Korea
}

\begin{abstract}
Electronic sports (eSports), or competitive video gaming, is a type of sport that has recently expanded its horizon from being a participatory sport to a spectator sport fueled by its wide popularity. In this regard, it is necessary to investigate why fans enjoy this new sports genre as a spectator sport. This study examines motivations of eSports spectators in different segments to gain a better understanding of the behaviors of this growing population. Specifically, this study aimed to (a) investigate eSports spectators' motivations to discover the motives for their attachment to eSports, using eleven different factors, and (b) explore differences in motivations among levels of addiction, fan identification, and passion. An analysis of 368 eSports fans showed that they valued the Achievement and Economics factors most in watching eSports. They even experienced a sense of achievement and a certain pecuniary advantage that real sports spectators experience. In addition, the Escape factor was identified as being the most important factor in explaining a passion for eSports-watching. This study also discovered significant differences between the eleven spectator motives, demonstrating the effectiveness of segmentation analysis in investigating the behaviors of sports fans. In particular, the Economics and Escape factors revealed meaningful differences between groups for all segments. This study showed that eSports spectators watch this new type of sports based on motivations that are similar to those of existing sports fans; furthermore, it identified significant differences in spectator motivations depending on their level of involvement in eSports.
\end{abstract}

Key words: media consumption, eSports, spectator motivation, addiction, passion, identification

\section{Introduction}

The distribution of computers and the development of the Internet has brought about great changes in sports, as they have in many aspects of our daily lives. Electronic sports (eSports) refers to the activity of enjoying a diversity of games using computers and the Internet. This new form of sports has experienced dramatic growth, and its popularity has even threatened traditional sports (Warman, 2015). The biggest advantage of eSports is that people can enjoy it in any place, at any time, with anyone around the world, as they are free from the restrictions of time and place through the benefit of the Internet. In response to the rising popularity of eSports, professional gamers, professional teams, and professional leagues were created, similar to those in existing traditional sports (e.g., ba-

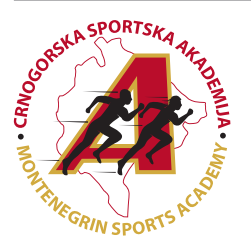

Correspondence:

C. Choi

Kyung Hee University, Department of Golf Industry, College of Physical Education, Yongin, Korea

E-mail: chulhwanchoi@yahoo.com 
seball, basketball, or soccer), and numerous global companies started investing huge amounts of money to buy sponsorships (Keiper, Manning, Jenny, Olrich, \& Croft, 2017). The sudden growth of eSports gave rise to another trend: people not only played eSports but also started watching them. In other words, eSports, as an emerging sports genre, has expanded from being a participation sport to a spectator sport (Jenny, Manning, Keiper, \& Olrich, 2016; Wagner, 2006).

On the Internet, people watch gameplay by professional gamers who belong to specific professional eSports teams sponsored by global companies; they also watch professionally commentated eSports games on TV, which are aired by broadcasters that bought broadcasting rights (Hamari \& Sjoblom, 2017). The number of fans worldwide who watch eSports through media has exceeded 205 million, while 28 million people in North America and Europe claim that they consider themselves eSports fans (Casselman, 2015). The objective figures of eSports surprisingly go well beyond those of traditional sports. This phenomenon became even more evident when eSports was adopted as one of the games in the 2018 Asian Games in Indonesia (Selvaraj, 2018). The fact that eSports has been adopted by an international mega-sporting event, where professional athletes of officially recognized traditional sports compete with each other and represent their own countries, is powerful evidence pointing to the status of eSports as a spectator sport. Nevertheless, until now, most literature regarding eSports, generally, and consumer behaviors in eSports in particular, have focused on consumers' participation motivations (Lee \& Schoenstedt, 2011). However, since a number of global eSports events have been held successfully, with an increasing number of spectators (Warr, 2014), it is necessary to consider why people like to watch eSports.

Sports fans watch their favorite sports for different reasons, and it is extremely important to investigate and understand spectator motivations in order to provide them with satisfactory results (Kim, Greenwell, Andrew, Lee, \& Mahoney, 2008). Researchers have studied the key motivational factors that influence the behaviors of sports spectators to understand their spectator motivations (Funk, Mahony, \& Ridinger, 2002; Trail \& James, 2001). Such attempts first materialized with the Sport Fan Motivation Scale (SFMS) developed by Wann (1995); the Motivation Scale for Sport Consumption (MSSC) was established later by Trail and James (2001), and the Sport Interest Inventory (SII) by Funk, Mahony, Nakazawa, and Hirokawa (2001). Owing to these efforts, a general idea regarding consumers' spectator motives has been established to a certain extent. However, endeavors to investigate consumer behaviors continue, as there can be more varied spectator motivations for a wide range of sports genres (Bilyeu \& Wann, 2002). In the same vein, this study will provide further insight to eSports spectators-a subject that has been little investigated to date.

As a new sport with exponential growth, it is important to understand why consumers are drawn to the sport to market the events more effectively. Furthermore, it is important to understand why different segments of spectators are watching eSports; consumer segmentation is therefore essential to investigate these consumer behaviors. Traditional sports consumers have often been segmented on the basis of fan identification (Trail, Anderson, \& Fink, 2000; Shapiro, Ridinger, \& Trail, 2013). The term "identification" has been defined as "an individual's orientation regarding affection or emotion toward different objectives" (Trail et al., 2000).
To understand sports fans' behaviors, various researchers have emphasized the importance of identification (Matsuoka, Chelladurai, \& Harada, 2003; Robinson \& Trail, 2005). In addition, a psychological variable such as "passion" has been utilized recently to segment sports consumers and understand their behaviors (Wakefield, 2016). According to Vallerand et al. (2003), "passion" is defined as "a strong inclination toward an activity that an individual likes, considers important, and invests time and effort in." Accordingly, the passion of sports fans is evaluated on the basis of how much they like the sport; how high a value they attribute to it; how much time, effort, and emotion they invest in it; and the sense of loss they experience when their team loses the sport (Wakefield, 2016). Passion is distinguished from general involvement and self-consciousness in that it includes the concept of desire. Therefore, a consumer with a high level of passion will more likely become an avid consumer (Thomson, MacInnis, \& Park, 2005).

Lastly, prior research investigating consumer behaviors related to eSports has often segmented consumers based on their level of addiction (Gaetan, Bonnet, Brejard, \& Cury, 2014; Lemmens, Valkenburg, \& Peter, 2009), where "addiction" is defined as "excessive and compulsive use of video games that results in social and/or emotional problems; despite these problems, the gamer is unable to control this excessive use" (Lemmens et al., 2009, p. 78). Most of the previous research focused on mental disorders (Loton, Borkoles, Lubman, Polman, 2015), social conflict (Beranuy, Carbonell, \& Griffiths, 2013), or sedentary lifestyles (Studer, Deline, N'Goran, Baggio, \& Gmel, 2016) as precursors to strong commitment, involvement, or identification in eSports. As such, measuring levels of addiction is an appropriate way to understand diverse types of eSports consumers.

The current study was guided by the following two research questions:

RQ1: Which eSports motives predict addiction, passion, and identification toward eSports?

RQ2: What are the differences in spectator motivations based on the level of game addiction, passion, and fan identification?

\section{Methods}

\section{Participants and data collection}

The target population for this study is people in the United States who watch eSports through various platforms (e.g., internet and/or television). Subjects were individuals over 18 years old who identify themselves as eSports fans. Using Amazon Mechanical Turk (MTurk), which is an online survey service provided from Amazon, Inc., the data collection procedure was implemented for 30 days with eSports fans. Prior to data collection, all research respondents were informed about research purposes, survey discontinuance, and human subjects protection requirements from the University's Institutional Review Board (IRB). The subjects were individuals who identified themselves as an eSport fan, reliable online respondent (i.e., A+ rated MTurk worker, HIT Approval Rate for all Requesters' HITs greater than 95, and number of HITs Approved greater than 100), and resident of the United States.

\section{Instruments and analysis}

An instrument (7-point Likert-type scale) was developed from the two most popular and extensively used scales: The Motivation Scale for Sport Consumption (MSSC; Trail \& Ja- 
mes, 2001) and the Sport Fan Motivation Scale (SFMS; Wann, 1995). Based on results of Cronbach's alpha coefficient and the average variance extracted (AVE), each motivational factor in both scales were compared to extract the most reliable motivational factors. As a result, Aesthetics, Drama, Knowledge, Physical Skills, Social Interaction, and Vicarious Achievement from the MSSC (Trail \& James, 2001), and Economics, Escape, and Entertainment from the SFMS (Wann, 1995) were selected.

The current study utilized and modified three different scales (7-point Likert-type scale) to segment eSports spectators: (a) the Game Addiction Scale (GAS) (Lemmens et al., 2009), including seven factors; salience, tolerance, mood modification, relapse, withdrawal, conflict, and problems, (b) the Points of Attachment Index (PAI) (Shapiro et al., 2013), including four factors; players, team, sport, and a general sport fan with 12 items, and (c) the four-item Passion scale, including "How passionate are you about eSports?", "During the season, to what degree do eSports occupy your mind?", "During the eSports season, how much do you prioritize your time so that you can follow your favorite eSport?", and "When it comes to how you feel about eSports in your life, I can't live without eSports" (Wakefield, 2016).

Lastly, prior to the main data analysis, confirmatory factor analysis (CFA) using SPSS AMOS 22.0 was performed to confirm the number of factors required in the data and which measured variable is related to which latent variable. Additionally, Cronbach's alpha was utilized to test reliability of variances.

\section{Results}

\section{Descriptive statistics}

A total of 608 surveys were distributed via MTurk, and 402 surveys were returned (approximately 66.12\% response rate) from respondents who self-identified as eSports consumers over the age of 18. After excluding 34 inappropriate surveys, a total of 368 surveys were finally utilized in this study. The sample of the current study consisted of 251 (68.2\%) males and 117 (31.8\%) females. In addition, $63.9 \%(n=235)$ of the sample were between the ages of 19 and 30 years old. General demographics of eSports showed that 61 percent of eSports spectators are male, and 38 percent are female (Casselman, 2015). Additionally, 56 percent of eSports fans were found to be between the ages of 21 and 35, and 28 percent were between the ages of 36 and 65 (Casselman, 2015). Hence, gathering data from the selected sample will be significant because more than 84 percent of eSports fans fall in to the target population for this study.

\section{Validity and reliability}

For all variables developed to explore spectator motivations (9 factors with 27 items) for eSports spectators, confirmatory factor analysis (CFA in SPSS AMOS version 22.0) was performed. All the observed fit statistics showed a good fit (Kline, $2005)$ to the data $(\chi 2=601.903, \mathrm{df}=288, \mathrm{p}<0.01$, normed fit in$\operatorname{dex}[\mathrm{NFI}]=.907$, comparative fit index $[\mathrm{CFI}]=.949$, root mean square error of approximation [RMSEA] $=.054$ ). Cronbach's alpha of items ranged from .712 to .961 , which exceeded the cut-off (>.70; Nunnally \& Bernstein, 1994).

\section{Research question 1}

To discover what motives are connected to their attachment (i.e., addiction, passion, and identification) to the eSport, three multiple regression analyses were conducted separately for the first research question. First, for the eSports addiction, Escape, Vicarious Achievement, and Economics were found to be significant predictors. Second, for the passion towards eSports, Vicarious Achievement, Economics, Escape, Knowledge, and Aesthetics were found to be significant predictors (Table 1). For the fan identification with eSports, Knowledge, Vicarious Achievement, and Economics were found to be significant predictors.

Table 1. Results of Multiple Regressions by Addiction, Passion, and Identification

\begin{tabular}{|c|c|c|c|c|c|c|c|}
\hline VARIABLES & IV s & B & $\beta$ & $\mathbf{t}$ & $\mathbf{R}^{2}$ & ADJ $R^{2}$ & $\mathbf{F}$ \\
\hline \multirow{3}{*}{ Addiction } & ESC & .51 & .32 & $5.89 * * *$ & \multirow{3}{*}{.30} & \multirow{3}{*}{.28} & \multirow{3}{*}{$16.91^{* * *}$} \\
\hline & $\mathrm{ACH}$ & .45 & .26 & $4.34 * * *$ & & & \\
\hline & ECO & .40 & .24 & $4.50^{* * *}$ & & & \\
\hline \multirow{2}{*}{ Passion } & $\mathrm{ACH}$ & .32 & .28 & $5.37^{* * *}$ & \multirow{2}{*}{.47} & \multirow{2}{*}{.46} & \multirow{2}{*}{$35.35^{* * *}$} \\
\hline & ECO & .23 & .22 & $4.64 * * *$ & & & \\
\hline \multirow{3}{*}{ Identification } & KNO & 1.09 & .39 & $8.37^{* * *}$ & \multirow{3}{*}{.60} & \multirow{3}{*}{.60} & \multirow{3}{*}{$59.08^{* * *}$} \\
\hline & $\mathrm{ACH}$ & .79 & .25 & $5.50 * * *$ & & & \\
\hline & ECO & .54 & .19 & $4.61^{* * *}$ & & & \\
\hline
\end{tabular}

Legend: $\mathrm{ACH}=$ Vicarious achievement, $\mathrm{AES}=$ Aesthetics, $\mathrm{ECO}=\mathrm{Economic}, \mathrm{ESC}=\mathrm{Escape}, \mathrm{KNO}=$ Acquisition of knowledge; ${ }^{* * *}<<.01$.

\section{Research questions 2}

To investigate differences in motivations among three groups (i.e., high, medium, and low) on the level of addiction, fan identification, and passion, three multivariate tests were performed separately. The detailed results were shown on Table 2. To identify high, medium, and low level of addiction, the average score of each factor was utilized to divide respondents into three groups (i.e., approximately $33.3 \%$ per group).

The first test revealed significant differences among three addiction groups (i.e., high, medium, and low) on the dependent variables [Wilks' lambda $=.706, \mathrm{~F}(18,714)=7.533, \mathrm{p}<0.001$, partial $\eta 2=.160]$. Based on adjusted alpha level using Bon- ferroni correction $(\mathrm{P}=0.001 / 3=.0003)$, the univariate ANOVAs for (a) Vicarious Achievement, (b) Economics, (c) Escape, and (d) Knowledge.

The second test revealed significant differences among three passion groups (high, medium, low) on the dependent variables [Wilks' lambda $=.613, \mathrm{~F}(18,714)=11.011, \mathrm{p}<0.001$, partial $\eta 2=.217]$. Based on adjusted alpha level using Bonferroni correction $(\mathrm{P}=0.001 / 3=.0003)$, the univariate ANOVAs for (a) Vicarious Achievement, (b) Aesthetics, (c) Economics, (d) Entertainment, (e) Knowledge, and (f) Social were statistically significant. 
Table 2. Results of MANOVAs: Differences in spectator motivations based on addiction, passion, and identification

\begin{tabular}{ccccc}
\hline IV & DV & df & $\mathrm{F}$ & $\eta^{2}$ \\
\hline \multirow{3}{*}{ Addiction } & ACH & 2 & $21.652^{* * * *}$ & .106 \\
& ECO & 2 & $24.486^{* * *}$ & .118 \\
& ESC & 2 & $38.256^{* * * *}$ & .173 \\
& KNO & 2 & $10.817^{* * * *}$ & .056 \\
\hline \multirow{5}{*}{ Passion } & ACH & 2 & $56.276^{* * * *}$ & 236 \\
& AES & 2 & $21.412^{* * *}$ & .105 \\
& ECO & 2 & $30.882^{* * *}$ & .145 \\
& ENT & 2 & $9.126^{* * *}$ & .048 \\
& KNO & 2 & $55.068^{* * *}$ & .232 \\
& SOC & 2 & $23.996^{* * *}$ & .116 \\
\hline \multirow{5}{*}{ Identification } & ACH & 2 & $85.401^{* * * *}$ & .319 \\
& AES & 2 & $26.423^{* * *}$ & .126 \\
& ECO & 2 & $37.905^{* * * *}$ & .172 \\
& ENT & 2 & $14.768^{* * *}$ & .075 \\
& ESC & 2 & $30.034^{* * *}$ & .141 \\
& KNO & 2 & $148.103^{* * *}$ & .450 \\
& PHY & 2 & $13.680^{* * * *}$ & .070 \\
& SOC & 2 & $41.628^{* * * *}$ & .186 \\
\hline
\end{tabular}

Legend: $\mathrm{ACH}=$ Vicarious achievement, $\mathrm{AES}=$ Aesthetics, $\mathrm{ECO}=$ Economic, ENT=Entertainment, $\mathrm{ESC}=$ Escape, $\mathrm{KNO}=$ Acquisition of knowledge, $\mathrm{PHY}=$ Physical skills, $\mathrm{SOC}=$ Social; ${ }^{* * *} \mathrm{p}<0.001$.

The third test revealed significant differences among three fan identification groups (high, medium, low) on the dependent variables [Wilks' lambda $=.456, \mathrm{~F}(18,714)=19.050$, $\mathrm{p}<0.001$, partial $\eta 2=.324]$. Based on adjusted alpha level using Bonferroni correction $(\mathrm{P}=0.001 / 3=.0003)$, the univariate ANOVAs for (a) Vicarious Achievement, (b) Aesthetics, (c)
Economics, (d) Entertainment, (e) Escape, (f) Knowledge, (g) Physical Skills, and (h) Social were statistically significant. Additionally, the follow-up Tukey post hoc analyses revealed significant differences among groups on variables. Detailed mean scores of each group on variables were reported Table 3.

Table 3. Mean scores for spectator motivations among groups based on addiction, passion, and identification

\begin{tabular}{cccccccccc}
\hline & ACH & AES & DRA & ECO & ENT & ESC & KNO & PHY & SOC \\
\hline Addiction & & & & & & & & & \\
High & 5.21 & 5.34 & 5.50 & 3.17 & 5.41 & 5.27 & 4.26 & 5.26 & 4.71 \\
Mid & 4.77 & 5.46 & 5.59 & 2.34 & 5.76 & 4.68 & 3.82 & 5.58 & 4.77 \\
Low & 3.95 & 4.90 & 5.40 & 1.71 & 5.40 & 3.53 & 3.22 & 4.96 & 4.14 \\
\hline Passion & & & & & & & & & \\
High & 5.58 & 5.74 & 5.69 & 3.23 & 5.80 & 5.31 & 4.77 & 5.57 & 5.27 \\
Mid & 4.69 & 5.32 & 5.53 & 2.34 & 5.64 & 4.63 & 3.93 & 5.28 & 4.51 \\
Low & 3.67 & 4.66 & 5.29 & 1.62 & 5.16 & 3.49 & 2.67 & 4.95 & 3.87 \\
\hline Identification & & & & & & & & & \\
High & 5.80 & 5.77 & 5.74 & 3.32 & 6.00 & 5.37 & 5.29 & 5.78 & 5.48 \\
Mid & 4.59 & 5.34 & 5.52 & 2.33 & 5.46 & 4.27 & 3.79 & 5.19 & 4.50 \\
Low & 3.46 & 4.53 & 5.23 & 1.48 & 5.11 & 3.71 & 2.18 & 4.82 & 3.62 \\
\hline
\end{tabular}

Legend: $\mathrm{ACH}=$ Vicarious achievement, $\mathrm{AES}=$ Aesthetics, $\mathrm{DRA}=$ Drama, $\mathrm{ECO}=$ Economic, $\mathrm{ENT}=$ Entertainment, $\mathrm{ESC}=\mathrm{Escape}, \mathrm{KNO}=\mathrm{Acquisi}-$ tion of knowledge, $\mathrm{PHY}=$ Physical skills, $\mathrm{SOC}=$ Social; Statistically significant higher mean scores between groups in bold.

\section{Discussion}

This study aimed to understand consumer behaviors of eSports spectators, using three distinct types of segmentation (e.g., GAS, Passion, and PAI). The research efforts contribute to (a) exploring which spectator motives predict attachment to eSports, and (b) investigating differences based on segments of eSports spectators. The results of this study revealed significant factors that motivate eSports fans' spectating behaviors, suggesting that eSports spectators value Achievement and Economics factors the most. Interestingly, the findings indicated that eSports fans also felt a sense of achievement and expected a certain pecuniary advantage through watching eSports, like spectators in general sports (Funk et al., 2002; Wann, Grieve, Zapalac, \& Pease, 2008). Furthermore, a noticeable finding was that the Escape factor was exceptionally strong in explaining addiction, unlike passion and fan identification. The result might be closely related to a finding from a previous study that people who report relative higher scores on addiction often show problems such as social conflict or isolation (Beranuy et al., 2013).

Additionally, this study confirmed the necessity of different segmentation approaches and identified significant differences from consumer to consumer, based on the level of involvement in eSports. Specifically, given that almost all results from 
eleven spectator motivations revealed statistically significant differences between groups (e.g., low, medium, and high), regardless of the types of segmentation, (a) the level of addiction, (b) passion, and (c) fan identification, these factors proved to be effective ways to segment spectators in eSports. Particularly, Economics and Escape showed statistically significant differences between groups on all segments and additional post hoc tests. As the level of attachment went from low to high regardless of the segment types, the mean scores of the two factors changed drastically. That is, the more people are attached to eSports, the more they are affected by Economics and Escape motivational factors. However, two factors (i.e., Drama and Entertainment in Addiction, and Drama in Passion) were not statistically significant between groups, indicating that most consumers were driven by these motives regardless of their level of attachment.

This study analyzed the consumer psychology of spectators of the newly emerging sports and suggested meaningful findings. The results provide important insights for understanding recent changes in the sports industries. Concretely, although eSports games are very different from traditional sports, the factors that motivate eSports consumers to watch eSports games were not very different from those for traditional sports. This may indicate that eSports can also be defined and recognized as a genre of sports. In addition, this study also discovered that, even though the behaviors of the same consumers are analyzed with regard to the same sports, the results may vary widely depending on how they are segmented and under what standards. This suggests that it is necessary to approach consumer behaviors from more diverse perspectives. The psychology of eSports spectators uncovered by this study certainly contributes to enriching the existing literature of spectator motivation studies. This study also demonstrated that passion and addiction are important segmentation approaches, apart from identification, which is the conventional variable of consumer segmentation analysis frequently used in previous studies. This is a meaningful contribution for future studies of consumer behavior.

\section{Limitations and Future Research}

There are several limitations in this study. First, this study did not classify the type of media the eSports spectators used, even though the media platforms they use vary. Spectator motives may also vary accordingly, because each media platform features different characteristics. In this respect, it would be vital for future studies to comparatively analyze spectator motives between watching sports on smartphones and watching them on television.

Finally, the age of study participants and the average duration of their daily eSports watching can be very important variables for eSports, as eSports are relatively more popular among young people, who use the Internet and computers more widely than older people. Nevertheless, they were not specifically analyzed in this study. Future research may obtain more meaningful results by introducing more relevant or significant variables. Continued attempts from more diverse perspectives will certainly contribute to a more concrete and accurate consumer analysis of eSports spectators.

\section{Acknowledgements}

There are no acknowledgements.

\section{Conflict of Interest}

The authors declare that there are no conflicts of interest.

Received: 21 November 2018 | Accepted: 17 December 2018 | Published: 01 February 2019

\section{References}

Beranuy, M., Carbonell, X., \& Griffiths, M. (2013). A qualitative analysis of online gaming addicts in treatment. International Journal of Mental Health and Addiction, 11(2), 149-161.

Bilyeu, J.K., \& Wann, D.L. (2002). An investigation of racial differences in sport fan motivation. International Sports Journal, 6(2), 94-106.

Casselman, B. (2015). Resistance is futile: esports is massive... and growing. Retrieved from http://www.espn.com/espn/story/_/id/13059210/esports-massive-industry-growing/.

Funk, D.C., Mahony, D.F., \& Ridinger, L.L. (2002). Characterizing consumer motivation as individual difference factors: Augmenting the Sport Interest Inventory (SII) to explain level. Sport Marketing Quarterly, 11, 33-43.

Funk, D.C., Mahony, D.F., Nakazawa, M., \& Hirakawa, S. (2001). Developing of the sport interest inventory (SII): Implications for measuring unique consumer motives at team sporting events. International Journal of Sports Marketing \& Sponsorship, 3, 291-316.

Gaetan, S., Bonnet, A., Brejard, V., \& Cury, F. (2014). French validation of the 7-item Game Addiction Scale for adolescents. European Review of Applied Psychology, 64(4), 161-168.

Hamari, J. \& Sjoblom, M. (2017). What is eSports and why do people watch it? Internet Research, 27(2), 211-232.

Jenny, S., Manning, R.D., Keiper, M.C., \& Olrich, T.W. (2016). Virtual(ly) athletes: Where eSports fit within the definition of "sport." Quest. doi:10.1080/00 336297.2016.1144517.

Keiper, M.C., Manning, R.D., Jenny, S., Olrich, T., \& Croft, C. (2017). No reason to LoL at LoL: The addition of eSports to intercollegiate athletic departments. Journal for the Study of Sports and Athletes in Education, 11(2), 143-160.

Kim, S., Greenwell, T.C., Andrew, D.P.S., Lee, J., \& Mahoney, D.F. (2008). An analysis of spectator motives in an individual combat sport: A study of mixed martial arts fans. Sport Marketing Quarterly, 17, 109-119.

Kline, R.B. (2005). Principles and practice of structural equation modeling (2nd ed.). New York, NY: Guilford Press.

Lee, D., \& Schoenstedt, L.J. (2011). Comparison of eSports and traditional sports consumption motives. ICHPER-SD Journal of Research, 6(2), 39-44.

Lemmens, J.S., Valkenburg, P., \& Peter, J. (2009). Development and validation of a game addiction scale for adolescents. Media Psychology, 12, 77-95.

Loton, D., Borkoles, E., Lubman, D., \& Polman, R. (2015). Video game addiction, engagement and symptoms of stress, depression and anxiety: The mediating role of coping. International Journal of Mental Health and Addiction, 14(4), 565-578.

Matsuoka, H., Chelladurai, P., \& Harada, M. (2003). Direct and interaction effects of team identification and satisfaction on intention to attend games. Sport Marketing Quarterly, 12(4), 244-253.

Nunnally, J.C., \& Bernstein, I.H. (1994). Psychometric theory (3rd ed.). New York, NY: McGraw-Hill.

Robinson, M. \& Trail, G.T. (2005). Relationships among spectator gender, motives, points of attachment and sport preference. Journal of Sports Management, 19, 58-80.

Selvaraj, J. (2018). eSports and the Asian Games-The future is now. ESPN. Retrieved from http://www.espn.com/espn/story/_/id/24541395/esports-asian-games-future-now/.

Shapiro, S., Ridinger, L., \& Trail, G.T. (2013). An analysis of multiple spectator consumption behaviors, identification, and future behavioral intentions within the context of a new college football program. Journal of Sport Management, 27, 130-145.

Studer, J., Deline, S., N'Goran, A., Baggio, S., \& Gmel, G. (2016). Video gaming disorder and sport and exercise in emerging adulthood: A longitudinal study. Behavior Medicine, 42(2), 105-111.

Thomson, M., MacInnis, D.J., \& Park, W.C. (2005). The ties that bind: Measuring the strength of consumers' emotional attachments to brands. Journal of Consumer Psychology, 15, 77-91.

Trail, G.T., \& James, J.D. (2001). The motivation scale for sport consumption: assessment of the scale's psychometric properties. Journal of Sport Behavior, 24(1), 108-127.

Trail, G.T., Anderson, D.F., \& Fink, J.S. (2000). A theoretical model of sport spectator consumption behavior. International. Journal of Sport Management, 1, 154-180.

Vallerand, R.J., Blanchard, C., Mageau, G.A., Koestner, R., Ratelle, C.F., Leonard M., \& Gagne, M. (2003). Les passions de l'ame: On obsessive and harmonious passion. Journal of Personality and Social Psychology, 85, 756-767. 
Wagner, M. (2006). On the scientific relevance of eSport. In J. Arreymbi, V.A. Clincy, O.L. Droegehorn, S. Joan, M. G. Ashu, J. A. Ware, S. Zabir, S. \& H. R. Arabnia (Eds), Proceedings of the 2006 International Conference on Internet Computing and Conference on Computer Game Development, CSREA Press, Las Vegas, NV, pp. 437-440.

Wakefield, J.C. (2016). Diagnostic issues and controversies in DSM-5: Return of the false positives problem. Annual Review of Clinical Psychology, 12, 105-132.

Wann, D.L. (1995). Preliminary validation of the sport fan motivation scale Journal of Sport and Social Issues, 19, 377-396.
Wann, D.L., Grieve, F.G., Zapalac, R.K., \& Pease, D.G. (2008). Motivational profiles of sport fans of different sports. Sport Marketing Quarterly, 17(1), 6-19.

Warman, P. (2015). The eSports economy: Trends, audience and revenue growth towards 2017 [PDF document]. Retrieved from http://www.slideshare. net/Newzoo/casual-connect-europewarmanesportsv2/.

Warr, P. (2014). eSports in numbers: Five mind-blowing stats. Red Bull, April 9. Retrieved from www.redbull.com/en/esports/stories/1331644628389/ esports-in-numbers-five-mind-blowing-stats (accessed June 1, 2018). 